\title{
New technique for analysing conjugated bile acids in gastric juice
}

\author{
D C Gotley, A P Morgan, M J Cooper
}

\begin{abstract}
A new technique of high performance liquid chromatography (HPLC) was developed for the analysis of conjugated bile acids in gastric juice. The assay is rapid, sensitive, and highly specific for bile acid conjugates over the range 30$10000 \mu \mathrm{mol} / 1$ and is not affected by the presence of food. Ten patients with a variety of common upper gastrointestinal disorders underwent continuous gastric aspiration for 16 hours, including a fasting, post-prandial, and nocturnal period, and aliquots of aspirates were analysed every two hours by the HPLC technique for the six most prevalent bile acid conjugates present in human hepatic bile. Intragastric bile acid concentrations were lowest in the post-prandial period and highest in the early hours of the morning. Conjugated bile acid proportions, or profiles, varied considerably from patient to patient, but tended to remain uniform over time in individual patients.
\end{abstract}

It is concluded that HPLC is superior to enzymatic techniques for the analysis of conjugated bile acids in the upper gastrointestinal tract.

Bile acids have been implicated in a variety of gastric and oesophageal disorders. ${ }^{1-3}$ The most commonly used analytical technique for measuring bile acids in aspirates from the upper gastrointestinal tract is the $3 \alpha$-hydroxysteroid dehydrogenase ( $3 \alpha-\mathrm{HSD})$ assay devised by Iwata and Yamasaki, ${ }^{4}$ adapted for analysis of duodenal aspirates by Fausa and Skalhegg, ${ }^{5}$ and validated for gastric samples by Collins. ${ }^{6}$ Recent reports of cross reactivity of the assay enzyme with ingested foodstuffs highlight the non-specific nature of this assay technique and its unreliability when used for post-prandial gastric specimens. ${ }^{78}$ The technique is further limited by a low sensitivity ${ }^{38}$ and is unable to quantify individual bile acid conjugates.

High performance liquid chromatography
(HPLC) using a reversed phase column and ultraviolet detection has been used to quantify bile acids in a variety of biological fluids, ${ }^{9-13}$ and recent refinement using the principle of "ion-pairing" has improved resolution. ${ }^{14}$ HPLC has advantages over the $3 \alpha$-HSD technique for bile acid analysis in the upper gastrointestinal tract: it is rapid and does not require derivatisation or time consuming preparation of samples. As far as we are aware a technique for HPLC analysis for bile acids in gastric juice or oesophageal refluxate has not yet been validated. Separate validation is necessary because gastric juice differs from other body fluids in its $\mathrm{pH}$, and it remains to be established whether the technique is unaffected by the presence of ingested foodstuffs. We developed and validated a technique of HPLC suitable for the quantitation of individual bile acid conjugates in gastric and oesophageal aspirates.

\section{Methods \\ VALIDATION STUDIES \\ Apparatus}

A Gilson 302 high performance liquid chromatograph, equipped with a Rheodyne high pressure sampling valve (model 71-25, USA) and a $20 \mu \mathrm{l}$ sample loop, was used. The chromatograph was fitted with a Gilson holochrome spectrophotometric ultraviolet detector at $210 \mathrm{~nm}$ and an Apple IIe microprocessor controller/programmer. The stationary phase comprised two columns in series (Altex Ultrasphere ODS $5 \mathrm{mU} ; 250 \mathrm{~mm} \times 4.6 \mathrm{~mm}$ ID, USA; and Varian micropak SP C18$5 \mathrm{mU} ; 150 \mathrm{~mm} \times 4 \mathrm{~mm}$ ID, USA). A Gilson Pri-column (SSI 05-0418) was used as a filter. All $\mathrm{pH}$ measurements were performed with an EIL $7030 \mathrm{pH}$ meter and combined glass electrode.

\section{Solvents and reagents}

Tetrabutylammonium phosphate (TBAP) and the sodium salts of glycine and taurine conjugates of cholate, chenodeoxycholate, and deoxycholate were obtained from commercial sources (Sigma, USA). Methanol, acetoni-

Table 1 Retention times and capacity factors for each of six bile acids assayed

\begin{tabular}{lllll}
\hline Bile acid & $\begin{array}{l}\text { Retention time } \\
\text { (minutes) }\end{array}$ & $\begin{array}{l}\text { Relative } \\
\text { retention time } \\
(G C D C)\end{array}$ & $\begin{array}{l}\text { Capacity factor } \\
\left(k^{\prime}\right)\end{array}$ & $\begin{array}{l}\text { Relative } \\
\text { capacity factor } \\
\left(r k^{\prime}\right)\end{array}$ \\
\hline Taurocholate (TC) & 9.0 & 0.552 & 0.667 & 0.33 \\
Glycocholate (GC) & 9.4 & 0.577 & 0.741 & 0.37 \\
Taurochenodeoxycholate (TCDC) & 12.6 & 0.773 & 1.333 & 0.66 \\
Taurodeoxycholate (TDC) & 13.9 & 0.853 & 1.574 & 0.78 \\
Glycochenodeoxycholate (GCDC) & 16.3 & 1.0 & 2.019 & 1.0 \\
Glycodeoxycholate (GDC) & 18.3 & 1.123 & 2.389 & 1.18 \\
\hline
\end{tabular}




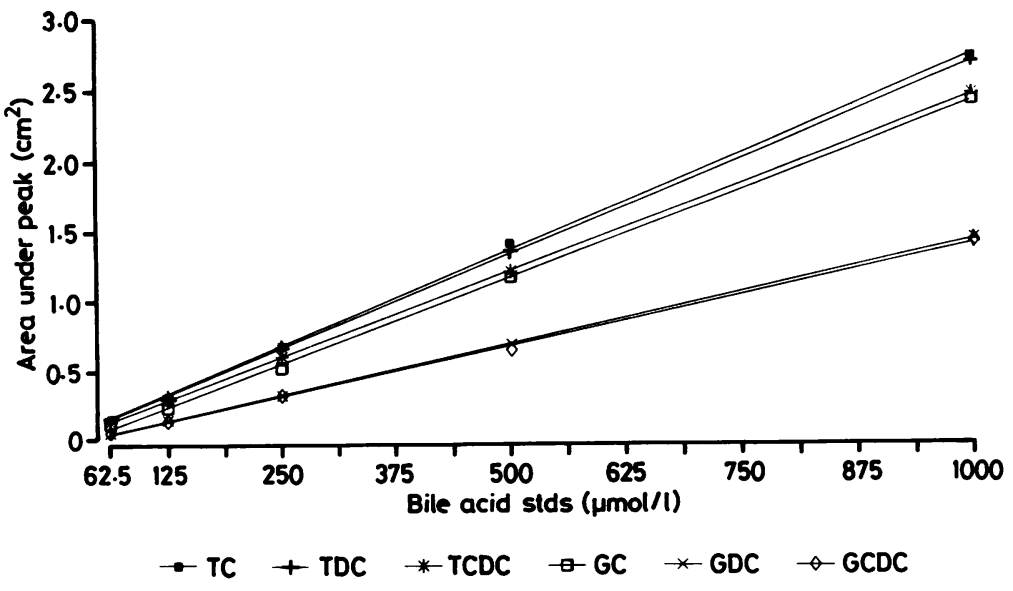

Figure 2 Bile acid calibration curves.

Table 2 Sensitivity of HPLC assay (62.5 micromolar standard solution was assayed 10 times)

\begin{tabular}{llrc}
\hline Bile acid & $\begin{array}{l}\text { Mean }(n=10) \\
(\mu \mathrm{mol} / \mathrm{l})\end{array}$ & $S D(S E M)$ & $\begin{array}{c}\text { \% Error } \\
\text { from mean }\end{array}$ \\
\hline Taurocholate & 64.6 & $4 \cdot 8(1.53)$ & $2 \cdot 3$ \\
Glycocholate & 61.2 & $5 \cdot 3(1.68)$ & $2 \cdot 7$ \\
Taurochenodeoxycholate & 59.6 & $12 \cdot 2(3.85)$ & 6.5 \\
Taurodeoxycholate & 62.0 & $6 \cdot 8(2 \cdot 14)$ & 3.5 \\
Glycochenodeoxycholate & 53.6 & $16 \cdot 0(5.07)$ & 9.5 \\
Glycodeoxycholate & 34.8 & $17.8(5.64)$ & 16.2 \\
\hline
\end{tabular}

Table 3 Recovery of bile acid standards added to bile contaminated gastric juice

\begin{tabular}{lccccc}
\hline Bile acid & Present & Added & Expected & Found & \% Recovery \\
\hline Taurocholate & $970 \cdot 3$ & 1200 & $2170 \cdot 3$ & $2145 \cdot 9$ & 98 \\
Glycocholate & $877 \cdot 2$ & 857 & $1734 \cdot 2$ & $1719 \cdot 5$ & $98 \cdot 3$ \\
& $5694 \cdot 3$ & 1200 & $6894 \cdot 3$ & $7034 \cdot 1$ & 117 \\
Taurochenodeoxycholate & $227 \cdot 1$ & 857 & $1084 \cdot 1$ & 1067 & 98 \\
& $265 \cdot 7$ & 1200 & $1465 \cdot 7$ & $1411 \cdot 6$ & $95 \cdot 5$ \\
Taurodeoxycholate & $159 \cdot 8$ & 857 & $1016 \cdot 9$ & $1089 \cdot 2$ & 107 \\
& 200 & 1200 & 1400 & 1467 & $105 \cdot 6$ \\
Glycochenodeoxycholate & $9 \cdot 9$ & 857 & $866 \cdot 9$ & $864 \cdot 7$ & $99 \cdot 7$ \\
& $3439 \cdot 7$ & 1200 & $4639 \cdot 7$ & $4799 \cdot 5$ & 113 \\
Glycodeoxycholate & 0 & 857 & 857 & 805 & 94 \\
& 0 & 1200 & 1200 & 1110 & $92 \cdot 5$ \\
Total & 0 & 857 & 857 & $833 \cdot 3$ & 97 \\
& $10568 \cdot 0$ & 7200 & 17768 & 17968 & 101 \\
& 1274 & 5142 & 6416 & $6378 \cdot 4$ & $99 \cdot 4$ \\
\hline
\end{tabular}

Table 4 Recovery of synthetic bile acids from three standard solutions

\begin{tabular}{lllll}
\hline Expected & $\begin{array}{l}\text { Found } \\
\text { mean }(n=5)\end{array}$ & $S D(S E M)$ & $\begin{array}{l}\text { Coefficient of } \\
\text { variation }\end{array}$ & $\%$ Recovery \\
\hline 7200 & 7162.28 & $20.08(8.98)$ & 0.28 & 99.5 \\
5143 & 5128.06 & $11.00(4.92)$ & 0.21 & 99.7 \\
2571 & 2385.52 & $67.98(30.40)$ & 2.85 & 92.8 \\
\hline
\end{tabular}

Table 5 Reproducibility ( 500 micromolar standard solution of bile acids was assayed on 14 consecutive days)

\begin{tabular}{lll}
\hline Bile acid conjugate & $\begin{array}{c}\text { Mean }(S D)(\mu \mathrm{mol} / \mathrm{l}) \\
(\boldsymbol{n}=14)\end{array}$ & $\begin{array}{l}\% \text { Deviation } \\
\text { from mean }\end{array}$ \\
\hline Taurocholate & $500(40 \cdot 3)$ & $8 \cdot 0$ \\
Glycocholate & $500(35 \cdot 6)$ & $7 \cdot 1$ \\
Taurochenodeoxycholate & $500(28 \cdot 5)$ & $5 \cdot 7$ \\
Taurodeoxycholate & $500(24 \cdot 9)$ & $5 \cdot 0$ \\
Glycochenodeoxycholate & $500(17 \cdot 4)$ & $3 \cdot 5$ \\
Glycodeoxycholate & $500(29 \cdot 7)$ & $5 \cdot 9$ \\
\hline
\end{tabular}

Table 6 Intra-assay variation (one sample was assayed 14 times)

\begin{tabular}{lcc}
\hline Bile acid conjugate & $\begin{array}{l}\text { Mean }(S D)(\mu \text { moll } / l) \\
(n=14)\end{array}$ & $\begin{array}{l}\% \text { Deviation } \\
\text { from mean }\end{array}$ \\
\hline Taurocholate & $171 \cdot 0(11 \cdot 2)$ & $6 \cdot 6$ \\
Glycocholate & $525 \cdot 0(14 \cdot 2)$ & $2 \cdot 7$ \\
Taurochenodeoxycholate & $95 \cdot 52(2 \cdot 67)$ & $2 \cdot 8$ \\
Taurodeoxycholate & $67 \cdot 7(0 \cdot 9)$ & 1.35 \\
Glycochenodeoxycholate & $457 \cdot 0(14 \cdot 9)$ & 3.26 \\
Glycodeoxycholate & $586 \cdot 5(18 \cdot 3)$ & 3.11 \\
Total conjugates & $1852 \cdot 7(24 \cdot 0)$ & $1 \cdot 26$ \\
\hline
\end{tabular}

trile, and hypersolve were obtained from BDH Ltd, Poole (UK). Double distilled water was provided by our own distillation plant (Fi-Stream, Fisons). Solvents and reagents were used without further purification.

\section{Preparation of samples}

Samples were thawed and $1 \mathrm{ml}$ was combined with ice cold methanol $(1: 2 \mathrm{v} / \mathrm{v})$. The sample was then centrifuged at $8 \times g$ for 10 minutes, passed through a $0.22 \mu \mathrm{m}$ Millex filter (Millipore, Molsheim, France), and $20 \mu \mathrm{l}$ were then injected directly into the sample loop.

\section{High performance liquid chromatography}

The mobile phase was prepared by mixing acetonitrile and double distilled water (54:46), and $0.4 \mathrm{M}$ tetrabutylammonium phosphate (TBAP) was added as the counter-ion. The $\mathrm{pH}$ was adjusted to 2.5 by the addition of orthophosphoric acid (specific gravity 1.75; Anular; BDH, UK). The mobile phase flow rate was $0.5 \mathrm{ml} / \mathrm{min}$ at $1500 \mathrm{psi}$ and was used at an ambient temperature of $22-23^{\circ} \mathrm{C}$. The ultraviolet detector was set at $210 \mathrm{~nm}$ with a range of 0.01 absorbence units for range. Elution time was 18 minutes per sample. Columns were occasionally backflushed with double distilled water at $50^{\circ} \mathrm{C}$, followed by methanol, acetonitrile, and finally the mobile phase. This prolongs column life and has allowed the processing of over 2000 samples without deterioration in column function.

\section{PATIENT STUDY}

Ten patients with a variety of upper gastrointestinal disorders were studied. Four had reflux oesophagitis, four non-ulcer dyspepsia, and two had a healed gastric ulcer. The median age was 58 years (range 33-83 years); there was an equal sex distribution. No patient had had previous gastric surgery or vagotomy, and three had undergone cholecystectomy. The aim of the study was to determine the bile acid profiles in gastric aspirates from these patients and to ascertain whether they varied from person to person, and diurnally and nocturnally.

After a six hour fast each patient had a size 14 Salem sump tube passed transnasally and positioned with its tip $12 \mathrm{~cm}$ below the lower oesophageal sphincter, as determined manometrically. Continuous aspiration was provided by an electric pump, and aspirate was collected in a flask over ice. A 16 hour study (starting at $\mathbf{1 7 0 0}$ hours) was divided into two hourly periods (giving eight specimens for each patient), allowing fasting, post-prandial, and nocturnal periods to be assessed. A standard meal was given at 1900 hours, which consisted of an egg salad sandwich, canned peaches, and $250 \mathrm{ml}$ of milk, providing 595 calories. ${ }^{8}$ A pause of 30 minutes during the meal was taken before sampling was started. Each two hour aliquot was centrifuged at $3000 \mathrm{rpm}$ for 20 minutes, decanted, and stored at $-70^{\circ} \mathrm{C}$ for later analysis. 
Table 7 Effect of food on bile acid assay: detection response in three solutions

\begin{tabular}{|c|c|c|c|c|}
\hline Standard solution & $\begin{array}{l}\text { Total bile acid } \\
\text { conjugates } \\
\text { (mean } n=5)\end{array}$ & $S D(S E M)$ & $95 \% C I$ & $\begin{array}{l}p \text { value } \\
(t \text { test })\end{array}$ \\
\hline $\begin{array}{l}285 \cdot 7 \mu \mathrm{M} \\
\text { Saline } \\
\text { Food }\end{array}$ & $\begin{array}{l}10 \cdot 16 \\
10 \cdot 33\end{array}$ & $\begin{array}{l}0.22(0.13) \\
0.27(0.15)\end{array}$ & $\begin{array}{r}9.90-10.42 \\
10.03-10.63\end{array}$ & $0 \cdot 3$ \\
\hline $\begin{array}{l}333 \cdot 3 \mu \mathrm{M} \\
\text { Saline } \\
\text { Food }\end{array}$ & $\begin{array}{l}11 \cdot 59 \\
11 \cdot 32\end{array}$ & $\begin{array}{l}0.29(0.10) \\
0.44(0.20)\end{array}$ & $\begin{array}{l}11 \cdot 39-11 \cdot 79 \\
10 \cdot 92-11 \cdot 72\end{array}$ & $0 \cdot 5$ \\
\hline $\begin{array}{l}571.4 \mu \mathrm{M} \\
\text { Saline } \\
\text { Food }\end{array}$ & $\begin{array}{l}19.93 \\
19.65\end{array}$ & $\begin{array}{l}0.28(0.16) \\
0.14(0.08)\end{array}$ & $\begin{array}{l}19 \cdot 61-20 \cdot 25 \\
19 \cdot 49-19 \cdot 81\end{array}$ & $0 \cdot 7$ \\
\hline
\end{tabular}

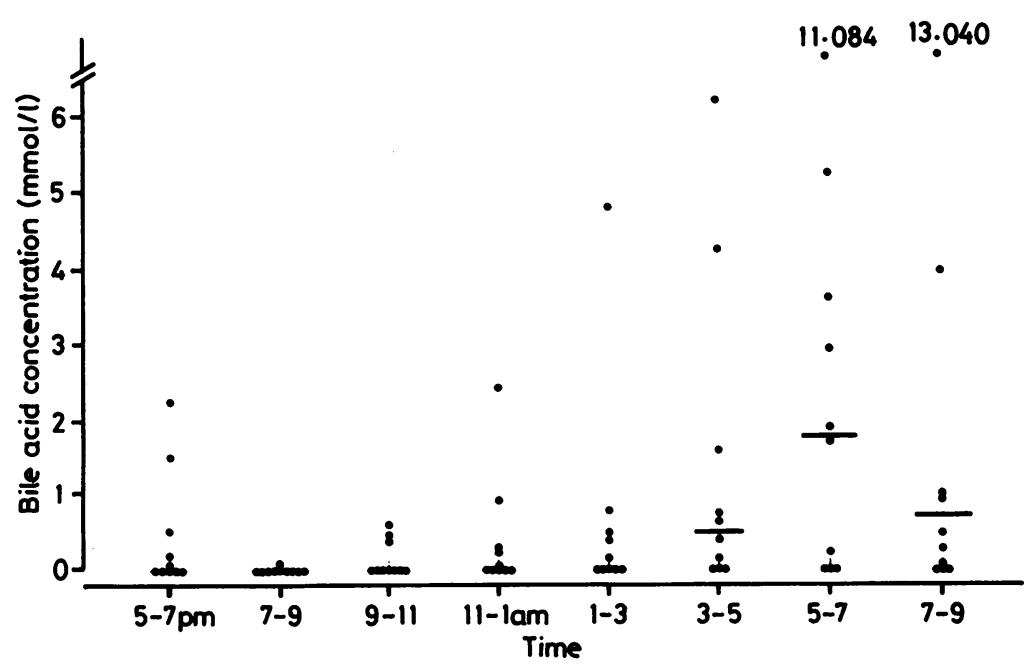

Figure 3 Bile acid concentrations in gastric aspirates during eight time periods.

\section{Results}

Separation of a standard mixture of glycine and taurine conjugated bile acids is shown in fig 1 . Column retention behaviour is described by the capacity factor $\left(k^{\prime}\right)$ and relative capacity factor ( $\mathbf{r k}^{\prime}$ - relative to glycochenodeoxycholic acid) (table 1).

\section{Quantitative analysis}

Known amounts of conjugated bile acids $(62 \cdot 5$ $1000 \mu \mathrm{mol} / \mathrm{l})$ were assayed to determine detection response. Calibration curves were calculated with these data (fig 2 ). The accuracy of the HPLC method is reflected in the small deviation of the plotted points from linearity, and sensitivity at $62.5 \mu \mathrm{mol} / 1$ was acceptable (table 2). Linearity was maintained from a minimum bile acid concentration of $30 \mu \mathrm{mol} / 1$ to at least $10 \mathrm{mmol} / \mathrm{l}$.

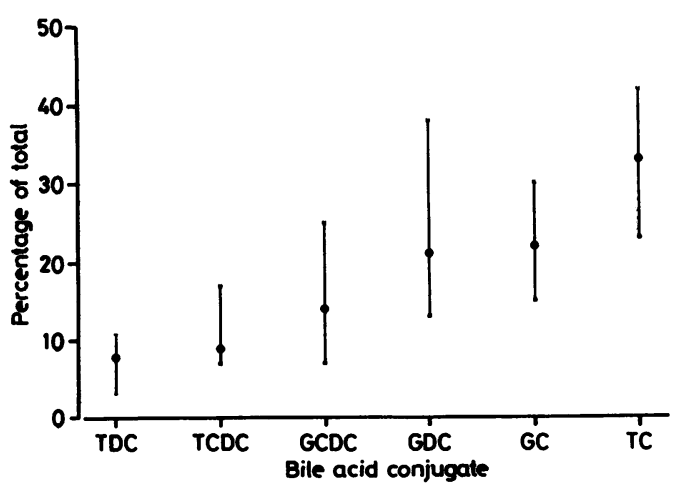

Figure 4 Proportions of the six different bile acid conjugates in gastric aspirates.
Recovery

Test samples were prepared by adding known amounts of synthetic bile acids to bile contaminated gastric aspirates. Two gastric specimens were each analysed in triplicate, and the mean values are presented in table 3 . Three standard solutions were prepared, and each was analysed five times. Recovery of total bile acid conjugates from standard solutions is shown in table 4.

\section{Reproducibility}

Reproducibility of the assay was assessed by repeated analysis of the same standard solution of synthetic bile acid conjugates on 14 different days (table 5). Intra-assay variability within the overall technique was tested by analysing a $20 \mu \mathrm{l}$ aliquot on 14 different days taken from the same sample of bile stained gastric aspirate. The results are shown in table 6 . Deviation from the mean ranged from 1.35 to $6 \cdot 6 \%$.

\section{Effect of food}

To assess the effect of food on the assay, three solutions of synthetic bile acids were prepared. An aliquot of each solution was mixed with either $0.9 \%$ (physiological) saline or with food substitute $(1: 1 \mathrm{v} / \mathrm{v})$. The food substitute was Fortison (Cow \& Gate Ltd, Trowbridge, Wiltshire, England), which is a balanced enteral feeding solution containing $4 \mathrm{~g}$ protein, $4 \mathrm{~g}$ fat, $12 \mathrm{~g}$ carbohydrates per $100 \mathrm{ml}$ water and a variety of essential vitamins and minerals. Each solution was then assayed for individual conjugated bile acids five times and the results were expressed as mean (standard deviation) of total conjugated bile acids (table 7). Food substitute did not interfere with the HPLC assay ( $\mathrm{p}>0 \cdot 3, t$-test).

\section{Gastric aspirates}

Of 80 two hour periods, bile acids were detected in gastric aspirates obtained during 51 $(64 \%)$ of them, and were quantifiable $(>30 \mu \mathrm{mol} / 1)$ in 38 specimens. Seventy nine per cent of specimens with bile acids were obtained during nocturnal sleep, and higher intragastric bile acid concentrations were found during the nocturnal period ( $\mathrm{p}<0.001$ Mann-Whitney U test) (fig 3). Only one of 10 post-prandial specimens contained bile acid (83 $\mu \mathrm{mol} / \mathrm{l})$.

Relative conjugated bile acid profiles were studied. These varied widely among patients (figs 4 and 5). Variation in bile acid profiles within patients from hour to hour also occurred but was much less pronounced (fig 6).

\section{Discussion}

The most commonly used analytical technique for bile acids, the $3 \alpha$-hydroxysteroid dehydrogenase assay, ${ }^{4}$ indirectly measures bile acid by relying on the reduction of nicotinamide-adenine dinucleotide (NAD) to NADH by the $3 \alpha$-hydroxyl group, released from the bile acid molecule during the enzymatic reaction. ${ }^{15}$ This reaction is not specific because the $\alpha$ moiety occurs in a variety of other sterols ${ }^{15}$ and is the probable explanation for high "bile 


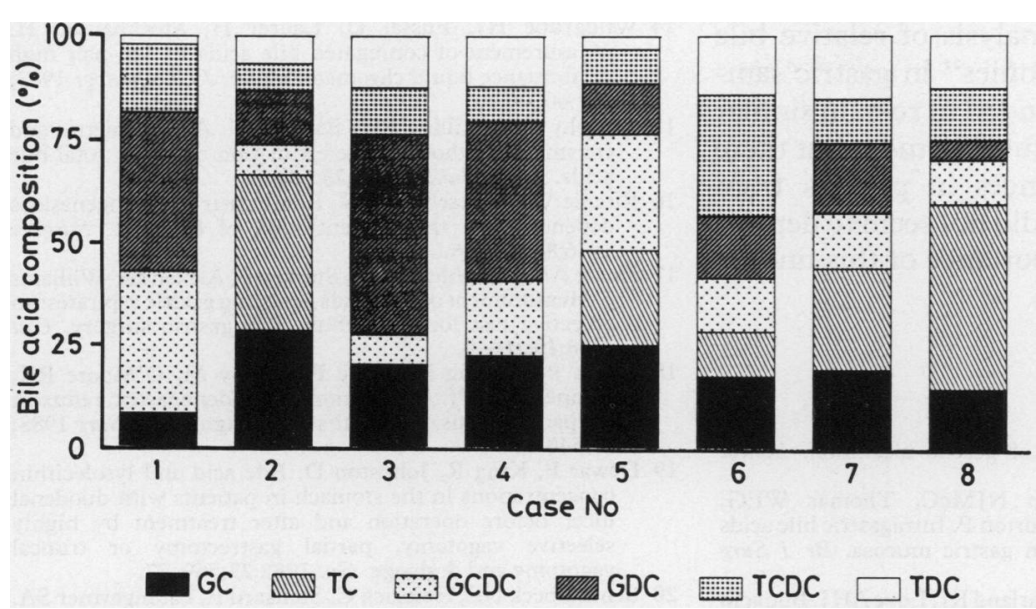

Figure 5 Median bile acid proportions, or profiles, in eight patients.

acid-like reactivity" found in homogenised test meals known to be bile acid free, ${ }^{8}$ and in stool specimens from which bile acids have been extracted ( $R$ Owen, personal communication). Previous reports show an increase in gastric bile acid concentrations within patients following a test meal using the $3 \alpha-$ HSD assay, ${ }^{16-18}$ and studies on the role of bile acids in the pathogenesis of gastric and duodenal disorders have generally focused on the post-prandial period as a result. ${ }^{19}$ This may be responsible for previous conflicting results. ${ }^{20}$ Our results show that HPLC is a sensitive, specific, and reproducible technique for the measurement of bile acid conjugates in gastric aspirates. We found bile acids in only one of 10 post-prandial gastric aspirates.

HPLC is specific for conjugated bile acids, relying on their individual ultraviolet absorbence. This provides an advantage over the $3 \alpha-$ HSD technique, which only measures total bile acid content. We validated the technique for the glycine and taurine conjugates of cholate, deoxycholate, and chenodeoxycholate which account for $98 \%$ of bile acids found in human bile. ${ }^{21}$ Because unconjugated bile acids are seldom found in gastric aspirates from patients with intact stomachs, ${ }^{22}$ the quantitation of individual and total bile acids depends almost entirely on the assay of these six bile acid conjugates. Conversely, up to $23 \%$ of bile acids in the stomachs of patients after gastrectomy may be unconjugated, ${ }^{2324}$ and their presence

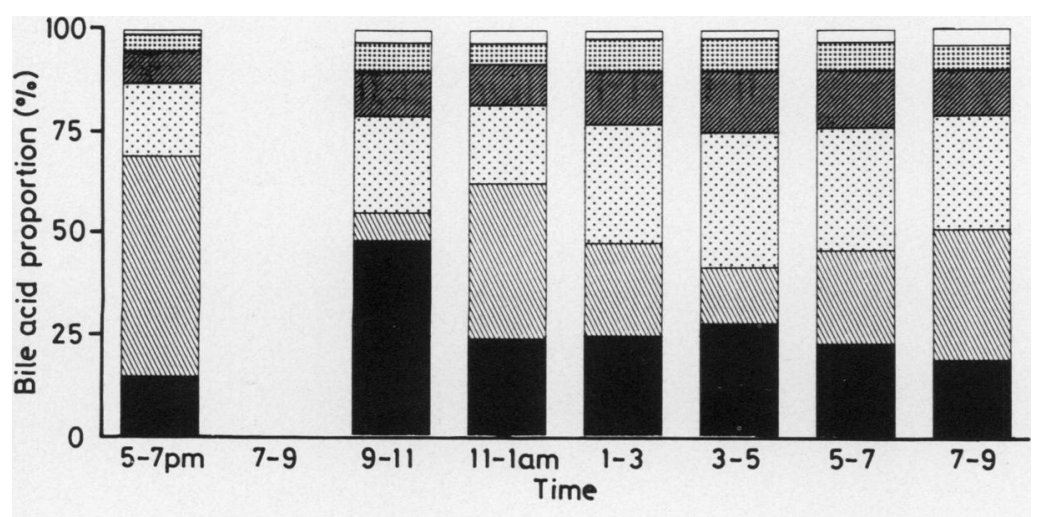

GC

Figure 6 An example of bile acid profiles during each time period in one patient. has been attributed to the action of bacteria. ${ }^{25}$ HPLC is not suitable for the analysis of unconjugated bile acids, for which gas-liquid chromatography is more appropriate. ${ }^{26}$

Another advantage of HPLC over $3 \alpha-\mathrm{HSD}$ is its increased sensitivity. The lower limit of accuracy of the $3 \alpha$-HSD method using spectrophotometry ranges from $62 \cdot 5-300 \mu \mathrm{mol} / 1,{ }^{38}$ which is the commonly encountered range of gastric bile acid concentrations. ${ }^{22}$ HPLC has a lower limit of detection of $2 \mu \mathrm{mol} / 1$, and can accurately quantify bile acids at concentrations above $62.5 \mu \mathrm{mol} / 1$.

Our HPLC method is based on that described by Wildgrube ${ }^{14}$ but differs in several important respects. Improved separation was obtained by acidification of the mobile phase to $\mathrm{pH} 2 \cdot 5$. Ionisation of bile acid conjugates is dependent on $\mathrm{pH}$ and results in a change in physicochemical behaviour. As the $\mathrm{pK}_{\mathrm{a}}$-that is, the $\mathrm{pH}$ at which the ionised:unionised molar ratio is equal-of glycine conjugates is around 2 , and that of the taurine conjugates is around 4 , retention times can be expected to be affected by a $\mathrm{pH}$ change from neutral to acid. The exact reason for the improved separation is not known, but it may be due to a combination of "ion pairing" and "ion suppression" effects. ${ }^{27}$ Prolonged retention of bile acids on the columns at this $\mathrm{pH}$ has not been encountered, nor has there been a problem of reduced column life as predicted by Wildgrube. ${ }^{14}$

The second respect in which this technique differs from previous methods is the use of a pair of stationary phases (columns) in series. At pH 2.5 using the $\mathrm{C}_{18}$ Micropak column, all bile acid conjugates were separated except those of glycocholate and taurocholate. Addition of the Altex column separated these bile acids without affecting the elution profile or duration.

The patients in this study had a greater proportion of gastric aspirates contaminated by bile acid during the nocturnal period than during the diurnal period. Moreover, concentrations of bile acid conjugates were higher during nocturnal sleep. Indeed, some samples contained amounts of bile similar to those found in bile duct samples, and nocturnal duodenogastric reflux is the culprit according to the alkaline $\mathrm{pH}$ measured in these samples. This finding is not new, having been first described by James and Pickering in 1949 in patients with gastric ulcers. ${ }^{28}$ Others have observed high bile acid concentrations in nocturnal gastric aspirates, ${ }^{22} 29$ and a large variation in bile acid contamination from hour to hour has been observed in individual patients. ${ }^{29}$ This is reflected in the pattern of bile acid content found in the oesophagus of patients with reflux oesophagitis..$^{30}$ Bile acids were rarely found in post-prandial aspirates. These results suggest that previous studies of bile acid reflux in patients with oesophageal and gastric disease which have been limited to short term, day time, or post-prandial studies, may not have been of sufficient duration to permit valid conclusions about their role in the pathogenesis of gastric disorders. Perhaps future studies of such patient groups should assess the whole nocturnal period. 
HPLC permits the analysis of relative bile acid proportions or "profiles" in gastric samples. Bile acid profiles tended to remain similar in each patient throughout the study, but there were noticeable differences in profiles from patient to patient which did not seem to depend on $\mathrm{pH}$. The clinical importance of this finding is not yet known.

1 DuPlessis DJ. Pathogenesis of gastric ulceration. Lance 1965;i:974-8.

2 Houghton PWJ, Mortensen NJMcC, Thomas WEG, Cooper MJ, Morgan AP, Burton P. Intragastric bile acids and histological changes in gastric mucosa. $\mathrm{Br} J$ Surg 1986;73:354-6.

3 Collins BJ, Crothers BJ, McFarland RJ, Love AHJ. Bile acid concentrations in the gastric juice of patients with erosive concentrations in the gastric juice

4 Iwata T, Yamasaki K. Enzymatic determination and thin layer chromatography of bile acids in blood. $J$ Biochem layer chromatog

5 Fausa O, Skalhegg BA. Quantitative determination of bile acids and their conjugates using thin layer chromatography and a purified 3-hydroxysteroid dehydrogenase. Scand J Gastroenterol 1974;9:249-54.

6 Collins BJ, Watt PCH, O'Reilly T, McFarland RJ, Love AHG. Measurement of total bile acids in gastric juice. Clin Pathol 1984;37:313-6.

7 Schmid B, Detarnowsky G, Layden T. Alkaline gastroesophageal reflux-role in esophageal injury. Gastroenterology 1981;80:1275.

8 enterology $1981 ; 80: 1275$. acids reflux into the esophagus?-A study of normal subjects and patients with gastroesophageal reflux disease. Gastroentrology 1987;92.571-5.

9 Bloch CA, Watkins JB. Determination of conjugated bile acids in human bile and duodenal fluid by reverse-phase high-performance liquid chromatography. $J$ Lipid Res 1978;19:510-13.

10 Parris NA. Liquid chromatographic separation of bile acids J Chromatogr 1977;133:273-9.

11 Nakayama F, Nakagaki $M$. Quantitative determination of bile acids in bile with reversed-phase high-performance bile acids in bile with r.

13 Teitz PS, Thistle JL, Miller LJ, LaRusso NF. Developmen and validation of a method for measuring the glycine and taurine conjugates of bile acids in bile by high-performance liquid chromatography. J Chromatogr 1984;336: 249-57.
14 Wildgrube $H J$, Fussel $U$, Laurer $H$, Stockhausen $H$. Measurement of conjugated bile acids by ion-pair high performance liquid chromatography. J Chromatogr 1983, 282:603-8.

15 Murphy GM, Billing BH, Baron DN. A fluorimetric and enzymatic method for the estimation of serum total bile acids. J Clin Pathol 1970;23:594-8.

16 Ritchie WP, Shearburn EW. Acute gastric ulcerogenesis is dependent on the concentration of bile salt. Surgery 1976;80:98-105.

17 Hoare AM, Keighley MRB, Starkey B, Alexander-Williams J. Measurement of bile acids in fasting gastric aspirates: an objective test for bile reflux after gastric surgery. Gut 1978;19:166-9.

18 Gillen P, Keeling P, Byrne PJ, Healy M, O'Moore RR, Hennessey TPJ. Implication of duodenogastric reflux in the pathogenesis of Barrett's oesophagus. Br J Surg 1988; the patho

19 Dewar P, King R, Johnston D. Bile acid and lysolecithin concentrations in the stomach in patients with duodenal ulcer before operation and after treatment by highly selective vagotomy, partial gastrectomy or truncal vagotomy and drainage. Gut 1982;23:569-77.

20 Schindlbeck NE, Heinrich C, Stellaard F, Paumgartner SA. Healthy controls have as much bile reflux as gastric ulcer patients. Gut 1987;28:1577-83.

21 Sjovall J. Bile acids in man under normal and pathological conditions. Clin Chim Acta 1960;5:33-41.

22 Poxon V, Hogg B, Youngs D, Morris DL, Keighley MRB. Incidence of bile reflux in gastric ulcer and after partial Incidence of bile reflux in gastric ulce

23 Sugiyama $\mathrm{Y}$, Sohma H, Ozawa M, et al. Regurgitant bile acids and mucosal injury of the gastric remnant after partial gastrectomy. Am J Surg 1987;153:399-403.

24 Matikainen M, Laatikainen T, Kalima T, Kivilaasko E. Bile acid composition and esophagitis after total gastrectomy. Am J Surg 1982;143:196-8.

25 Domellof L, Reddy BS, Weisburger JH. Microflora and deconjugation of bile acids in alkaline reflux after partial gastrectomy. Am J Surg 1980;140:291-5.

26 Owen RW, Thompson MH, Hill MJ. Analysis of metabolic profiles of steroids in faeces of healthy subjects undergoing profiles of steroids in faeces of healthy subjects undergoing chenodeoxycholic acid treatment by liquid gel chromatography and gas liquid chromatography-

27 Lu DS, Vialle J, Tralongo H, Longeray R. Retention behaviour of bile acids in Ion suppression and ion pai chromatography on bonded phases. J Chromatogr 1983, 268:1-18.

28 James AH, Pickering GW. The role of gastric acidity in the pathogenesis of peptic ulcer. Clin Sci 1949;8:181-210.

29 Gotthard R, Bodemar G, Tjadermo M, Tobiasson P, Walan A. High gastric bile acid concentration in prepyloric ulcer patients. Scand J Gastroenterol 1985;20:439-46.

30 Gotley DC, Morgan AP, Cooper MJ. Bile acid concentrations in the refluxate of patients with reflux oesophagitis. $B$ J Surg 1988;75:587-90. 